\title{
Vagal Stimulation Modulates Inflammation through a Ghrelin Mediated Mechanism in Traumatic Brain Injury
}

\author{
Vishal Bansal, ${ }^{1}$ Seok Yong Ryu, ${ }^{1,2}$ Nicole Lopez, ${ }^{1}$ Sarah Allexan, ${ }^{1}$ Michael Krzyzaniak, ${ }^{1}$ \\ Brian Eliceiri, ${ }^{1}$ Andrew Baird, ${ }^{1}$ and Raul Coimbra ${ }^{1,3}$
}

\begin{abstract}
Traumatic brain injury (TBI) releases a cascade of inflammatory cytokines. Vagal nerve stimulation (VNS) and ghrelin have known anti-inflammatory effects; furthermore, ghrelin release is stimulated by acetylcholine. We hypothesized VNS decreases post-TBI inflammation through a ghrelin-mediated mechanism. TBI was created in five groups of mice: sham, TBI, TBI/ghrelin, TBI/ VNS, and TBI/VNS/ghrelin receptor antagonist (GRa). Serum and tissue ghrelin, and serum TNF- $\alpha$ were measured. Ghrelin increased following VNS $2 \mathrm{~h}$ post-TBI compared to sham or TBI. At $6 \mathrm{~h}$, TBI and TBI/VNS/GRa had increased TNF- $\alpha$ compared to sham while TBI/VNS and TBI/ghrelin had TNF- $\alpha$ level comparable to sham. The highest ghrelin was measured in stomach where TBI decreased ghrelin in contrast to an increase by VNS. In conclusion, VNS increased serum ghrelin and decreased TNF- $\alpha$ following TBI. This was abrogated with GRa. Our data suggests that ghrelin plays an important role in the anti-inflammatory effects of VNS following TBI.
\end{abstract}

KEY WORDS: traumatic brain injury; inflammation; vagus nerve; ghrelin; neuroenteric axis.

\section{INTRODUCTION}

Traumatic brain injury (TBI) continues to be a multibillion dollar healthcare epidemic, causing death, long-term hospitalization, and prolonged disability [1]. Most current TBI therapies are targeted to prevent the sequelae of intracranial hypertension, optimize oxygenation, and tissue perfusion [2]. Recently, various clinical and animal studies have highlighted the importance of mitigating TBI-induced alterations in homeostasis to improve outcomes [3]. A recent retrospective study has shown that exposure to beta blockade during hospitalization following TBI decreases the risk of mortality despite the fact that patients were older, had higher injury severity scores, and had greater comorbidities [4]. What has yet to be elucidated, however, are the

\footnotetext{
${ }^{1}$ Department of Surgery, Division of Trauma, Surgical Critical Care and Burns, University of California San Diego, 200 W. Arbor Drive \#8896, San Diego, CA 92103, USA

${ }^{2}$ Department of Emergency Medicine, Inje University, Sanggye Paik Hospital, Seoul, South Korea

${ }^{3}$ To whom correspondence should be addressed at Department of Surgery, Division of Trauma, Surgical Critical Care and Burns, University of California San Diego, 200 W. Arbor Drive \#8896, San Diego, CA 92103, USA. E-mail: rcoimbra@ucsd.edu
}

molecular and physiologic mechanisms behind these observed clinical effects. We, and others, have postulated that preventing the post-TBI inflammatory surge may prevent the systemic inflammatory response syndrome, sepsis and multi-system organ failure $[5,6]$. Recently, we have shown that electrical vagus nerve stimulation (VNS) decreases post-TBI inflammation determined by lower levels of TNF- $\alpha$ and prevents intestinal injury determined by histology and decreased intestinal permeability [5]. Tracey et al. has shown that VNS, in a mouse model of sepsis, decreases mortality and the surge of inflammatory cytokines likely mediated through acetylcholine binding to macrophage nicotinic receptors [7].

The orexigenic hormone ghrelin, described in 1999, has been shown to have several anti-inflammatory properties in addition to its known effect on pituitary regulation and food intake [8]. Wu et al. have shown that intravenous ghrelin in septic mice decreases levels of the pro-inflammatory cytokines IL-1 and IL-6 [9]. Furthermore, the ghrelin receptor has been localized to the dorsal motor nucleus of the vagus in the brain indicating that ghrelin may regulate or be regulated by the vagus nerve [10]. Other evidence demonstrates that acetylcholine increases serum ghrelin levels, further 
implicating the involvement of the vagus nerve in ghrelin regulation [11]. Whether VNS prevents inflammation by a ghrelin mediated pathway is unknown. We hypothesized that electric VNS decreases post-TBI inflammatory cytokines through a ghrelin mediated mechanism.

\section{MATERIALS AND METHODS}

\section{Mouse TBI Model}

Animal experiments, including anesthesia, TBI, and recuperation, were approved through the university Institutional Animal Care and Use Committee (Approval \#S08110). Male Balb/c mice (20-24 g) were obtained from The Jackson Laboratory (Sacramento, CA, USA) and placed under a 12-h light and dark cycle. A weight drop TBI model, as previously described, was used to cause a right-sided cerebral contusion [5, 12]. Briefly, animals were anesthetized with $3 \%$ inhaled isoflurane. Each animal ( $n=8$ in each group) was manually secured and its head shaved with an electric clipper after which a vertical incision was made over the cranium and using a surgical drill, a burr hole, $4 \mathrm{~mm}$ in diameter, $1 \mathrm{~mm}$ lateral, and $1 \mathrm{~mm}$ posterior to the bregma was created to expose the dura mater. A 250-g metal rod was dropped from a height of $2 \mathrm{~cm}$ onto the exposed dura mater. The incision was closed with vet bond and buprenorphine $(100 \mu \mathrm{L})$ was injected subcutaneously for analgesia. Food and water were provided ad libitum. Animals were sacrificed, between 11:00 A.M. and 2:00 P.M., following cardiac puncture by cervical dislocation. In one arm, surgical abdominal vagotomy was performed immediately prior to vagal nerve stimulation and TBI through an upper-midline laparotomy incision. The gastroesophageal junction was identified and the dorsal and ventral vagus nerve were visualized and ligated on the distal esophagus with an Olympus SZ61 stereomicroscope (Leeds Precision Instruments, Minneapolis, MN, USA).

\section{Vagal Nerve Stimulation}

Following induction of general anesthesia with inhaled isoflurane, a right cervical neck incision was performed and the right cervical vagus nerve exposed [5]. Vagal nerve stimulation was performed using a VariStim III probe (Medtronic Xomed, Jacksonville, FL, USA) at $2 \mathrm{~mA}$ for $10 \mathrm{~min}$. The incision was closed with interrupted silk sutures and the animal was immediately subjected to TBI as previously described. Sham animals underwent right cervical incision and exposure of the vagus nerve but did not receive stimulation.

\section{Ghrelin and Ghrelin Antagonist Administration}

Animals in the ghrelin group $(n=8)$ received two doses of intraperitoneal (IP) ghrelin $(10 \mu \mathrm{g})$ immediately prior to and $1 \mathrm{~h}$ after TBI. The dosing and timing of ghrelin administration was determined from previous experiments showing that IP ghrelin has a rapid onset of action and its response is potentiated by a second IP injection within $4 \mathrm{~h}[13,14]$. Select animals received $6 \mathrm{mg} / \mathrm{kg}$ IP of a commercially available selective ghrelin antagonist ([d-Lys-3]-GHRP-6; AnaSpec, San Jose, CA, USA) before VNS.

\section{Levels of Serum TNF- $\alpha$ and Ghrelin}

Serum TNF- $\alpha$ levels were measured in sham or at 2 , 4, and $6 \mathrm{~h}$ following TBI in all groups, using a commercially available ELISA kit ( $\mathrm{R} \& \mathrm{D}$ system, Minneapolis, MN, USA). Values are reported as picogram per milliliter. Active serum ghrelin levels were measured in serum post-TBI in each group using a commercially available ELISA kit (Linco Research, St. Charles, MO, USA).

\section{Tissue Levels of Ghrelin}

Active tissue ghrelin levels were measured in stomach, intestine, brain, lung, and liver $2 \mathrm{~h}$ post-TBI in each group ( $n=6$ animals in each group) using a commercially available ELISA kit (Linco Research, St. Charles, MO, USA). Protein was extracted by homogenizing tissue in $500 \mu \mathrm{L}$ of ice-cold tissue protein extraction reagent containing $1 \%$ protease inhibitor and 1\% phosphatase inhibitor (Pierce Biotechnology, Rockford, IL, USA). Homogenates were centrifuged at $10,000 \times \mathrm{g}$ for $5 \mathrm{~min}$. The supernatant was obtained and stored at $-70^{\circ} \mathrm{C}$. Values are reported as picogram per milliliter.

\section{Statistical Analysis}

Values are expressed as mean \pm standard error of the mean. The statistical significance among groups was determined by $t$ test or analysis of variance with Bonferroni correction where appropriate, and a $p$ value $<0.05$ was considered statistically significant. 


\section{RESULTS}

\section{Levels of Serum TNF- $\alpha$}

Levels of serum TNF- $\alpha$ were measured by ELISA in all groups with the highest levels observed in TBI at $6 \mathrm{~h}$ compared to sham $(34.4 \pm 1.9$ vs. $22.9 \pm 1.4 \mathrm{pg} / \mathrm{ml} ; p<$ $0.001)$. VNS prevented the increase in TNF- $\alpha$ following TBI reducing levels to that of sham $(34.4 \pm 1.9 v s .21 .8 \pm$ $1.0 \mathrm{pg} / \mathrm{ml} ; p<0.03$; Figs. 1 and 2$)$. Likewise, exogenous ghrelin also prevented the increase in TNF- $\alpha$ following TBI reducing levels to that similar to sham and vagal stimulation (34.4 \pm 1.9 vs. $24.0 \pm 1.5 \mathrm{pg} / \mathrm{ml} p<0.02$; Fig. 2). In contrast, in animals treated with a ghrelin antagonist, VNS did not decrease serum TNF- $\alpha$ levels which remained elevated $6 \mathrm{~h}$ post-TBI $(34.4 \pm 1.9 v s$. $34.9 \pm 2.9 \mathrm{pg} / \mathrm{ml} ; p=\mathrm{NS}$; Fig. 2).

\section{Serum Levels of Ghrelin}

Serum levels of ghrelin were measured by ELISA at 2, 4, and $6 \mathrm{~h}$ following TBI, TBI $+\mathrm{VNS}$, and TBI+ $\mathrm{VNS}+$ vagotomy. Compared to baseline (656.7 \pm $189 \mathrm{pg} / \mathrm{ml})$, ghrelin levels in the TBI alone group were unchanged at $2 \mathrm{~h}(652.2 \pm 73 \mathrm{pg} / \mathrm{ml} ; p=\mathrm{NS})$ and trended lower at $4 \mathrm{~h}(531.6 \pm 27 \mathrm{pg} / \mathrm{ml} ; p=\mathrm{NS})$ and $6 \mathrm{~h}$ $(442 \pm 21 \mathrm{pg} / \mathrm{ml} ; p=\mathrm{NS})$. Following VNS however, ghrelin levels increased significantly compared to baseline and TBI at $2 \mathrm{~h}(1,200.0 \pm 162 \mathrm{pg} / \mathrm{ml} ; p<$ $0.01)$ and $4 \mathrm{~h}(850.2 \pm 33 \mathrm{pg} / \mathrm{ml} ; p=0.03)$ but decreased to levels of sham and TBI alone at $6 \mathrm{~h}$ (541.4 $\pm 25 \mathrm{pg} / \mathrm{ml} ; p=\mathrm{NS}$; Fig. 3). Animals undergoing surgical vagotomy, prior to VNS and TBI, had ghrelin levels similar to TBI alone at $2 \mathrm{~h}(578.3 \pm 107.3 \mathrm{pg} / \mathrm{ml} ; p=$

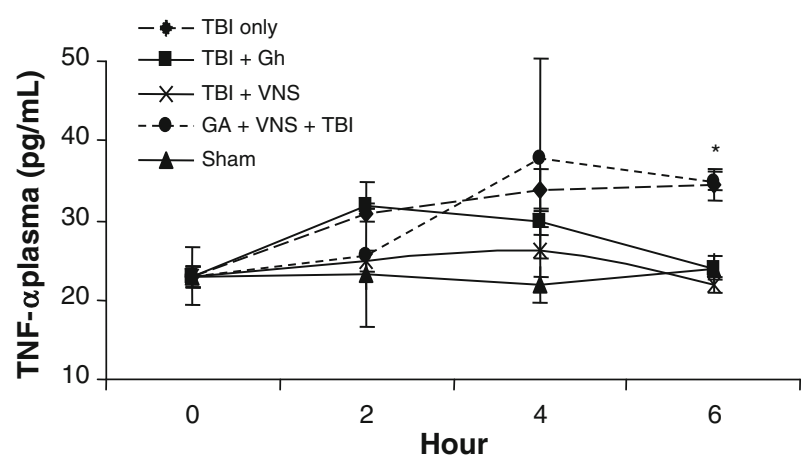

Fig. 1. Levels of serum TNF- $\alpha 2,4$, and $6 \mathrm{~h}$ following TBI in all groups. The highest mean levels were observed in TBI at $6 \mathrm{~h}$ compared to sham $\left(34.4 \pm 1.9\right.$ vs. $\left.22.9 \pm 1.4 \mathrm{pg} / \mathrm{ml} ;{ }^{*} p<0.03\right)$. VNS prevented the increase in TNF- $\alpha$ following TBI reducing levels to that of sham $(22.9 \pm 1.4 v s .21 .8 \pm$ $1.0 \mathrm{pg} / \mathrm{ml}, \dagger p=\mathrm{NS}$ ).

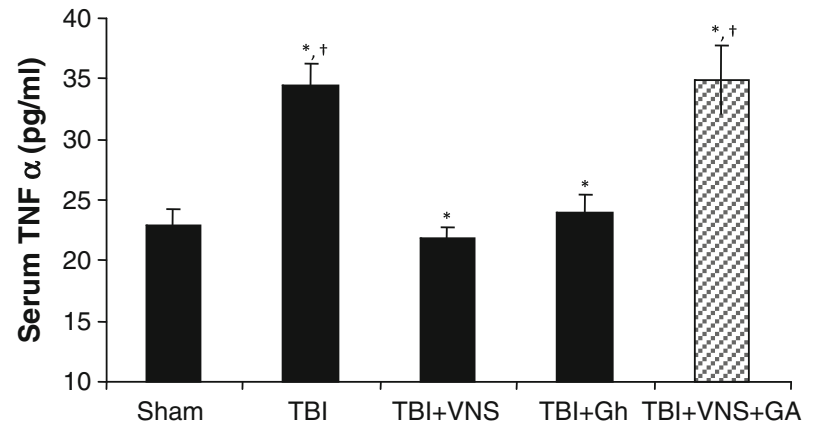

Fig. 2. Levels of TNF- $\alpha 6 \mathrm{~h}$ following TBI and exogenous ghrelin (Gh). Gh prevented the increase in TNF- $\alpha$ following TBI $(34.4 \pm 1.9$ vs. $\left.24.0 \pm 1.5 \mathrm{pg} / \mathrm{ml} ; *^{*}<0.02\right)$ reducing mean levels to that similar to sham and vagal stimulation. $(22.9 \pm 1.4$ vs. $24.0 \pm 1.5 \mathrm{pg} / \mathrm{ml} ; \dagger p=$ NS). Blocking the Gh receptor via a ghrelin antagonist ([d-Lys-3]GHRP-6) prevents the VNS decrease of serum TNF- $\alpha$ levels. The addition of a ghrelin antagonist (GA) preceding VNS and TBI prevented VNS induced reduction of mean serum TNF- $\alpha(34.4 \pm 1.9$ vs. $34.9 \pm 2.9 ; \mathrm{pg} / \mathrm{ml}, p=\mathrm{NS})$.

NS) and decreased compared to TBI+VNS ( $p=0.03)$. Ghrelin levels remained comparable to TBI at $4 \mathrm{~h}$ but decreased to levels similar to TBI and TBI+VNS at $6 \mathrm{~h}$.

\section{Tissue Levels of Ghrelin}

Tissue levels of ghrelin were measured in sham, $2 \mathrm{~h}$ post-TBI and $2 \mathrm{~h}$ post-TBI+VNS. Extracted protein

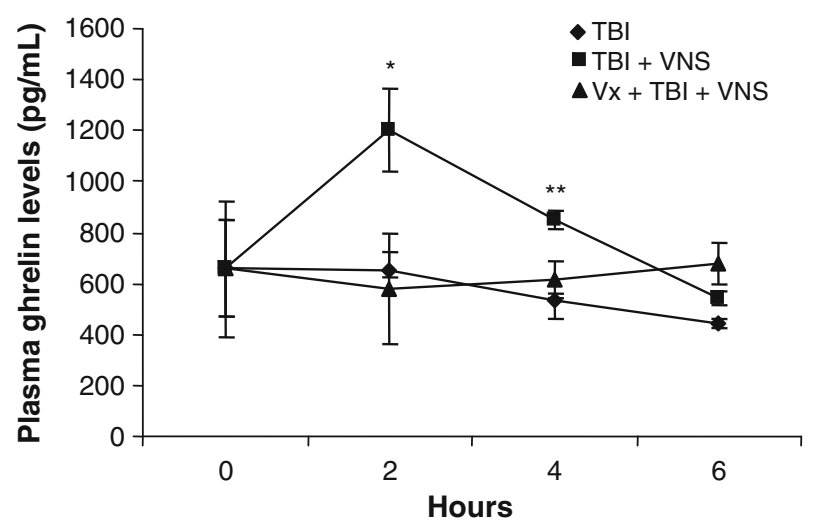

Fig. 3. Post-TBI mean serum Gh levels increase following VNS. Compared to baseline $(656.7 \pm 189 \mathrm{pg} / \mathrm{ml})$, Gh levels in TBI were unchanged at $2 \mathrm{~h}(652.2 \pm 73 \mathrm{pg} / \mathrm{ml} ; p=\mathrm{NS})$, trended lower at $4 \mathrm{~h}(531.6 \pm$ $27 \mathrm{pg} / \mathrm{ml} ; p=\mathrm{NS})$ and at $6 \mathrm{~h}(442 \pm 21 \mathrm{pg} / \mathrm{ml} ; p=\mathrm{NS})$. In VNS, Gh levels increased significantly compared to baseline and TBI at $2 \mathrm{~h}$ ($1,200.0 \pm 162 \mathrm{pg} / \mathrm{ml} ; * p<0.01)$ and $4 \mathrm{~h}(850.2 \pm 33 \mathrm{pg} / \mathrm{ml} ; * * p=0.03)$ but decreased to levels of sham and TBI alone at $6 \mathrm{~h}(541.4 \pm 25 \mathrm{pg} / \mathrm{ml}$; $p=\mathrm{NS})$. Gh levels did not increase in vagotomized animals that underwent VNS with levels similar to TBI alone at $2 \mathrm{~h}(578.3 \pm 107.3 \mathrm{pg} / \mathrm{ml}$; $p=\mathrm{NS})$ and decreased compared to TBI+VNS $(p=0.03)$. 
from stomach, intestine, brain, lung, and liver were measured for ghrelin, of which stomach had the highest levels of ghrelin followed by small intestine (Fig. 4). Compared to sham, post-TBI stomach had 4,780土 $232 \mathrm{pg} / \mathrm{ml}$ of ghrelin. Post-TBI ghrelin levels decreased to $4,037 \pm 137 \mathrm{pg} / \mathrm{ml}$ compared to sham $(p=0.05)$. However, VNS increased ghrelin levels significantly compared to TBI and trended higher compared to sham $(5,223 \pm 414 \mathrm{pg} / \mathrm{ml} ; p=0.04, p=0.06)$.

\section{DISCUSSION}

It is now well-established that increasing parasympathetic tone, through vagal nerve stimulation, decreases inflammation in various models of physiologic insult including cecal ligation and puncture, LPS injection, severe burn injury and TBI $[5,15,16]$. Tracey et al. has shown, in a murine sepsis model, that VNS prior to endotoxin injection decreases serum TNF- $\alpha$ and improves animal survival [17]. Current evidence explaining these findings suggests that VNS increases levels of synaptic acetylcholine which bind to $\alpha-7$ muscuranic receptor of immune cells (i.e., macrophages) and consequently decreases the release of TNF- $\alpha$ [18]. Vagotomized animals lose this effect and exhibit elevated levels of TNF- $\alpha$ with aggravation of lethal shock. Recently, we have shown that VNS prevents an increase in TNF- $\alpha$ following TBI and prevents intestinal injury as determined by improving histopathology and decreasing intestinal permeability [5]. The mechanism of these findings are unclear, and may well be similar to the mechanism of preventing TNF- $\alpha$ release by macrophages as demonstrated by the Tracey group. However, TBI has global and unique physiologic effects. These systemic sequelae are complex and affect virtually every organ including the cardiovascular, respiratory, gastrointestinal, and neuroendocrine systems $[6,19]$. There are several proposed etiologies behind these observations including a post-TBI adrenergic surge, decreased sympathetic tone, and a surge in inflammatory cytokines. Several investigators have attempted to modulate the response of neurogenic injury by varying medical regimens attenuating sympathetic activity by beta blockade [4, 20]. In an early study, Walter et. al. [21] has demonstrated that an early adrenergic blockade confers improved survival and overall outcome in patients with subarachnoid hemorrhage. Two recent, retrospective studies in the trauma population have shown that exposure to beta blockade, during hospitalization for TBI, improve overall outcomes and decrease the risk of mortality [4, 20]. These observations, coupled with laboratory data, have lead several authors to demonstrate that increasing parasympathetic tone, via electrical VNS, prevents inflammation and organ dysfunction following various injury models.

Beyond the anti-inflammatory effects, the vagus nerve serves as the conduit for neuroenteric communi-

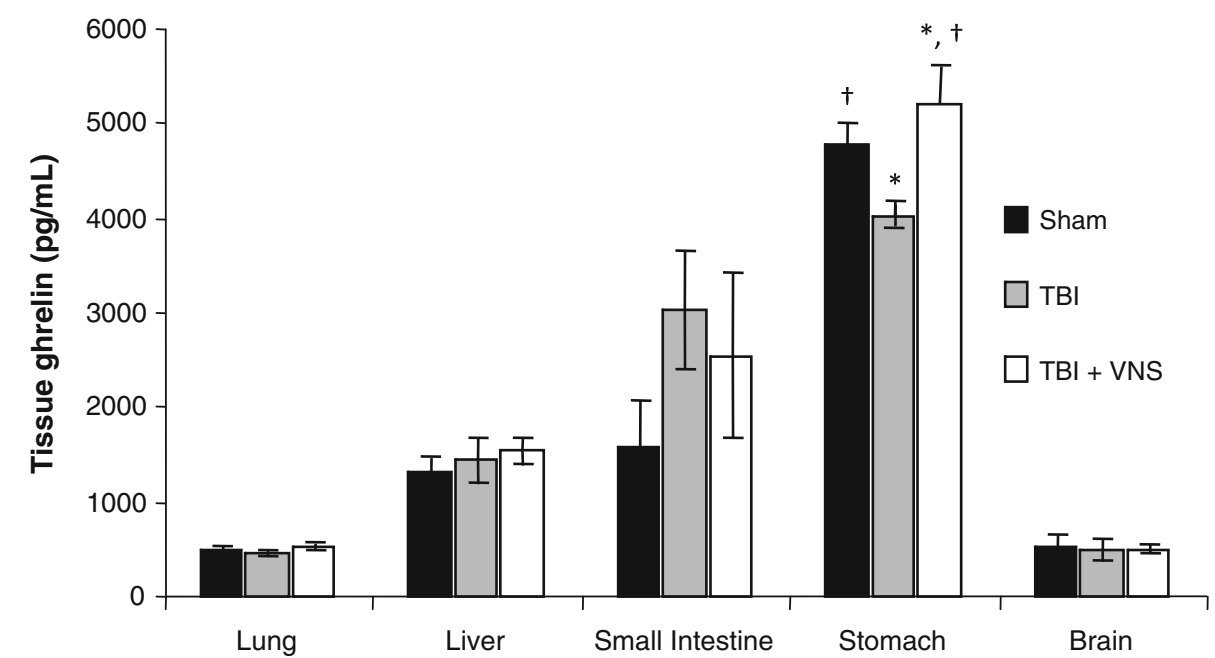

Fig. 4. VNS stimulation significantly increases stomach Gh levels $2 \mathrm{~h}$ following TBI. Tissue levels of Gh were measured in stomach, intestine, brain, lung, and liver. Stomach had the highest levels of Gh followed by small intestine. Compared to sham stomach Gh levels $(4,780 \pm 232 \mathrm{pg} / \mathrm{ml})$, post-TBI Gh levels decreased to $4,037 \pm 137 \mathrm{pg} / \mathrm{ml}\left({ }^{*} p=0.05\right)$. However, VNS increased mean Gh levels significantly compared TBI and trended higher compared to sham $\left(5,223 \pm 414 \mathrm{pg} / \mathrm{ml} ;{ }^{*} p=0.04 ; \dagger p=0.06\right)$. 
cation where increased vagus nerve activity, both central and peripheral, leads to increased gastrointestinal motility, increased pancreatic exocrine function and changes in neuroendocrine profiles [22]. The hormone ghrelin, predominantly produced in the stomach and small bowel, has been shown to influence central vagus nerve activity. Wu et al. has shown that exogenous ghrelin, administered in a mouse model of endotoxemia, downregulates inflammatory cytokine TNF- $\alpha$ and IL-6 release through activating the vagus nerve, suggesting that ghrelin may link the central nervous and the immune system [9]. Under this paradigm, ghrelin increases vagus nerve activity which consequently increases acytelcholine and therefore decreases release of TNF- $\alpha$ from macrophages and monocytes. Accordingly, our lab has recently reported exogenous ghrelin prevents intestinal injury and intestinal permeability following TBI [23]. However, the question of whether VNS, in and of itself, actually changes tissue and serum levels of ghrelin needs to be investigated.

The anti-inflammatory activity of ghrelin has only recently been recognized. Current data suggests that ghrelin binds to ghrelin receptors located on macrophages [24]. This action decreases phosphorylation of $\mathrm{NFKB}$ and thereby decreases the transcription of inflammatory cytokines such as TNF- $\alpha$ and IL-6. In another study, $\mathrm{Wu}$ et al. [25] demonstrated that exogenous ghrelin, given in septic mouse models, prevented gut barrier dysfunction and reduced circulating levels of HMGB-1, emphasizing the antiinflammatory actions of ghrelin. Additionally, Koch et al. [26], in an analysis of critically ill patients, demonstrated that higher endogenous ghrelin levels detected early in the patients' hospital course correlated with increased survival. Given that vagus activity has several effects on the gastrointestinal system, we postulated that VNS increases serum ghrelin and the subsequent increase in ghrelin was responsible, at least in part, to decrease post-TBI inflammation.

As in our previous TBI studies, we report that VNS decreased serum TNF- $\alpha$ following TBI. Exogenous ghrelin also decreased post-TBI serum TNF- $\alpha$ with a magnitude very similar to the observed TNF- $\alpha$ decrease by VNS. Furthermore, pre-treating animals with a ghrelin receptor antagonist abrogated the effects of VNS indicating that the increase in ghrelin is important in attenuating post-TBI inflammation. Taken together, ghrelin levels, whether administered exogenously or increased by VNS, decrease serum TNF- $\alpha$ following TBI. Wu et al. showed that exogenous ghrelin decreased macrophage derived TNF- $\alpha$ in sepsis. Their cytokine measurements were taken $20 \mathrm{~h}$ after the initial septic insult as the animals were receiving a continuous ghrelin infusion [6]. In our data, serum ghrelin levels peak at $2 \mathrm{~h}$ following VNS and trends downwards thereafter. Yet, post-TBI serum TNF- $\alpha$ remains low at $6 \mathrm{~h}$ despite ghrelin levels returning to baseline. This finding is not entirely unexpected since this may reflect a delayed effect a pulse of ghrelin may have on inflammatory cytokine transcription and release. It is unknown how long the anti-inflammatory effect of ghrelin lasts. A longer time course would be needed to further elucidate this question. Nevertheless, given these findings, the anti-inflammatory effects of VNS may partly be mediated by increased ghrelin release from the gastrointestinal system, specifically the stomach. In this regard, we have also shown that serum ghrelin levels increase significantly following VNS, where stomach tissue was found to have the highest levels of ghrelin. These results coincide with another study where free ghrelin release from isolated rat stomach was increased by adding acetylcholine [11]. Similarly, Hosoda et al. [27] have shown that serum ghrelin levels acutely drop following vagotomy in a mouse model and are only restored after $48 \mathrm{~h}$ of normal feeding. Interestingly, our data shows higher levels of ghrelin in small intestine following TBI when compared to sham and TBI+VNS. Even though this finding was not statistically significant, it is possible that post-TBI-induced intestinal motility dysfunction may have an effect on small bowel tissue ghrelin levels. This would be an interesting area of investigation. The exact mechanism explaining why VNS releases ghrelin is yet unknown. Perhaps acytelcholine, released from neuroenteric synapses following VNS, causes increased expression and excretion of ghrelin from gastrointestinal neuroendocrine cells similar to other hormones such as gastrin and cholecystokinin. It is plausible that while exogenous ghrelin may increase vagus nerve signaling, other gastrointestinal hormones, such as leptin, may serve to inhibit further vagus nerve activity. Indeed, leptin has been shown to increase TNF- $\alpha$ and IL-6 release from macrophages and evidence exists showing that leptin concentrations may be regulated by the central nervous system [28-31]. Given our findings and the current literature, gastrointestinal hormones such as ghrelin seem to modulate cytokine release and expression, however, the exact interplay between parasympathetic tone, ghrelin regulation, and overall inflammation needs further study. 
In summary, following TBI, TNF- $\alpha$ levels are decreased with both electric vagus nerve stimulation and exogenous ghrelin. VNS increases serum ghrelin which is mostly derived from the stomach. Inhibiting the ghrelin receptor prevents the anti-inflammatory effects of vagus nerve stimulation following TBI. Our data suggests that the release of ghrelin plays an important role in the antiinflammatory effects of VNS following TBI.

\section{Limitations}

It is important to recognize that ghrelin, like other hormones, fluctuates according to feedings and circadian cycles. In order to limit variations secondary to time of day, we measured all baseline ghrelin levels between 8:00 and 11:00 A.M. and sacrificed all animals between 11:00 A.M. and 2:00P.M. We did not account for ghrelin variation secondary to food intake. It is possible, that post-TBI animals did not have the same volume of oral consumption following injury altering ghrelin levels. A more formal study examining the effects of TBI, enteral feeds, time of day, and ghrelin levels would be an important future study.

\section{ACKNOWLEDGMENTS}

This research was supported in part by the 2009 Inje Research and Scholarship Foundation.

Open Access. This article is distributed under the terms of the Creative Commons Attribution Noncommercial License which permits any noncommercial use, distribution, and reproduction in any medium, provided the original author(s) and source are credited.

\section{REFERENCES}

1. McGarry, L.J., D. Thompson, F.H. Millham, L. Cowell, P.J. Snyder, W.R. Lenderking, and M.C. Weinstein. 2002. Outcomes and costs of acute treatment of traumatic brain injury. The Journal of Trauma 53: $1152-1159$.

2. Bratton, S.L., R.M. Chestnut, J. Ghajar, F.F. McConnell Hammond, O. A. Harris, R. Hartl, G.T. Manley, A. Nemecek, D.W. Newell, G. Rosenthal, et al. 2007. Guidelines for the management of severe traumatic brain injury. I. Blood pressure and oxygenation. Journal of Neurotrauma 24(Suppl 1): S7-S13.

3. Baguley, I.J., R.E. Heriseanu, I.D. Cameron, M.T. Nott, and S. Slewa-Younan. 2008. A critical review of the pathophysiology of dysautonomia following traumatic brain injury. Neurocritical Care 8: $293-300$.
4. Cotton, B.A., K.B. Snodgrass, S.B. Fleming, R.O. Carpenter, C. D. Kemp, P.G. Arbogast, and J.A. Morris Jr. 2007. Beta-blocker exposure is associated with improved survival after severe traumatic brain injury. The Journal of Trauma 62: 26-33. discussion 33-25.

5. Bansal, V., T. Costantini, S.Y. Ryu, C. Peterson, W. Loomis, J. Putnam, B. Elicieri, A. Baird, and R. Coimbra. 2010. Stimulating the central nervous system to prevent intestinal dysfunction after traumatic brain injury. Journal of Trauma 68(5): 1059-1064.

6. Kemp, C.D., J.C. Johnson, W.P. Riordan, and B.A. Cotton. 2008. How we die: the impact of nonneurologic organ dysfunction after severe traumatic brain injury. The American Surgeon 74: 866-872.

7. Parrish, W.R., M. Rosas-Ballina, M. Gallowitsch-Puerta, M. Ochani, K. Ochani, L.H. Yang, L. Hudson, X. Lin, N. Patel, S.M. Johnson, et al. 2008. Modulation of TNF release by choline requires alpha7 subunit nicotinic acetylcholine receptor-mediated signaling. Molecular Medicine 14: 567-574.

8. Kojima, M., H. Hosoda, Y. Date, M. Nakazato, H. Matsuo, and K. Kangawa. 1999. Ghrelin is a growth hormone-releasing acylated peptide from stomach. Nature 402: 656-660.

9. Wu, R., W. Dong, X. Cui, M. Zhou, H.H. Simms, T.S. Ravikumar, and P. Wang. 2007. Ghrelin down-regulates proinflammatory cytokines in sepsis through activation of the vagus nerve. Annals of Surgery 245: 480-486.

10. Zhang, W., T.R. Lin, Y. Hu, Y. Fan, L. Zhao, E.L. Stuenkel, and M.W. Mulholland. 2004. Ghrelin stimulates neurogenesis in the dorsal motor nucleus of the vagus. Journal de Physiologie 559: 729-737.

11. Shrestha, Y.B., K. Wickwire, and S.Q. Giraudo. 2009. Direct effects of nutrients, acetylcholine, CCK, and insulin on ghrelin release from the isolated stomachs of rats. Peptides 30: 1187-1191.

12. Bansal, V., T. Costantini, L. Kroll, C. Peterson, W. Loomis, B. Eliceiri, A. Baird, P. Wolf, and R. Coimbra. 2009. Traumatic brain injury and intestinal dysfunction: uncovering the neuro-enteric axis. Journal of Neurotrauma 26(8): 1353-1359.

13. Qiu, W.C., Z.G. Wang, R. Lv, W.G. Wang, X.D. Han, J. Yan, Y. Wang, Q. Zheng, and K.X. Ai. 2008. Ghrelin improves delayed gastrointestinal transit in alloxan-induced diabetic mice. World Journal of Gastroenterology 14: 2572-2577.

14. Wren, A.M., C.J. Small, H.L. Ward, K.G. Murphy, C.L. Dakin, S. Taheri, A.R. Kennedy, G.H. Roberts, D.G. Morgan, M.A. Ghatei, and S.R. Bloom. 2000. The novel hypothalamic peptide ghrelin stimulates food intake and growth hormone secretion. Endocrinology 141: 4325-4328.

15. Costantini, T.W., V. Bansal, C.Y. Peterson, W.H. Loomis, J.G. Putnam, F. Rankin, P. Wolf, B.P. Eliceiri, A. Baird, and R. Coimbra. 2010. Efferent vagal nerve stimulation attenuates gut barrier injury after burn: modulation of intestinal occludin expression. Journal of Trauma 68(6): 1349-1354. discussion 1354-1346.

16. Tracey, K.J. 2007. Physiology and immunology of the cholinergic antiinflammatory pathway. The Journal of Clinical Investigation 117: 289-296.

17. Tracey, K.J. 2002. The inflammatory reflex. Nature 420: 853-859.

18. Rosas-Ballina, M., M. Ochani, W.R. Parrish, K. Ochani, Y.T. Harris, J.M. Huston, S. Chavan, and K.J. Tracey. 2008. Splenic nerve is required for cholinergic antiinflammatory pathway control of TNF in endotoxemia. Proceedings of the National Academy of Sciences of the United States of America 105: 11008-11013.

19. Zygun, D.A., J.B. Kortbeek, G.H. Fick, K.B. Laupland, and C.J. Doig. 2005. Non-neurologic organ dysfunction in severe traumatic brain injury. Critical Care Medicine 33: 654-660.

20. Inaba, K., P.G. Teixeira, J.S. David, L.S. Chan, A. Salim, C. Brown, T. Browder, E. Beale, P. Rhee, and D. Demetriades. 2008. Beta-blockers in isolated blunt head injury. Journal of the American College of Surgeons 206: 432-438. 
21. Walter, P., G. Neil-Dwyer, and J.M. Cruickshank. 1982. Beneficial effects of adrenergic blockade in patients with subarachnoid haemorrhage. British Medical Journal (Clinical Research ed. 1981) 284: 1661-1664.

22. Li, Y. 2007. Sensory signal transduction in the vagal primary afferent neurons. Current Medicinal Chemistry 14: 25542563.

23. Bansal, V., S.Y. Ryu, C. Blow, T. Costantini, W. Loomis, B. Eliceiri, A. Baird, P. Wolf, and R. Coimbra. 2010. The hormone ghrelin prevents traumatic brain injury induced intestinal dysfunction. Journal of Neurotrauma 27(12): 2255-2260.

24. Waseem, T., M. Duxbury, H. Ito, S.W. Ashley, and M.K. Robinson. 2008. Exogenous ghrelin modulates release of pro-inflammatory and anti-inflammatory cytokines in LPS-stimulated macrophages through distinct signaling pathways. Surgery 143: 334-342.

25. Wu, R., W. Dong, X. Qiang, H. Wang, S.A. Blau, T.S. Ravikumar, and P. Wang. 2009. Orexigenic hormone ghrelin ameliorates gut barrier dysfunction in sepsis in rats. Critical Care Medicine 37: 2421-2426.
26. Koch, A., E. Sanson, A. Helm, S. Voigt, C. Trautwein, and F. Tacke 2010. Regulation and prognostic relevance of serum ghrelin concentrations in critical illness and sepsis. Critical Care 14(3): R94.

27. Hosoda, H., and K. Kangawa. 2008. The autonomic nervous system regulates gastric ghrelin secretion in rats. Regulatory Peptides 146: 12-18.

28. Acampa, M., F. Guideri, J. Hayek, P. Blardi, A. De Lalla, M. Zappella, and A. Auteri. 2008. Sympathetic overactivity and plasma leptin levels in Rett syndrome. Neuroscience Letters 432: 69-72.

29. German, J., F. Kim, G.J. Schwartz, P.J. Havel, C.J. Rhodes, M.W. Schwartz, and G.J. Morton. 2009. Hypothalamic leptin signaling regulates hepatic insulin sensitivity via a neurocircuit involving the vagus nerve. Endocrinology 150: 4502-4511.

30. Vaughan, T., and L. Li. 2010. Molecular mechanism underlying the inflammatory complication of leptin in macrophages. Molecular Immunology 47(15): 2515-2518.

31. La Cava, A., C. Alviggi, and G. Matarese. 2004. Unraveling the multiple roles of leptin in inflammation and autoimmunity. Journal of Molecular Medicine 82: 4-11. 